\title{
Acessibilidade do Turismo no Parque Nacional Serra da Capivara - PI
}

\author{
Tourism Accessibility in Parque Nacional Serra da Capivara - PI
}

\author{
Accesibilidad del Turismo en el Parque Nacional Serra da Capivara - PI
}

Stella Maria Sousa Carvalho ${ }^{1}$

\section{Resumo}

O turismo proporciona inúmeros benefícios, tanto para as destinações quanto para as pessoas que o praticam. Entretanto, nem todas as pessoas se beneficiam com a atividade, como deficientes e pessoas com mobilidade reduzida, pois não podem usufruir dos espaços e atrativos turísticos devido à falta de adaptações. Assim, esta pesquisa tem como objetivo discutir e analisar a infraestrutura do Parque Nacional Serra da Capivara - PI, Patrimônio Cultural brasileiro, no que diz respeito à acessibilidade. Para tanto, realizou-se uma pesquisa bibliográfica sobre o tema e em uma pesquisa de campo, durante os meses de julho a setembro de 2010, com observação direta da área, coleta de dados, entrevistas e conversas informais. Percebeu-se, então, que a infraestrutura do Parque possui algumas adaptações, destinadas principalmente a cadeirantes, mas de maneira superficial e em alguns casos, incorreta.

Palavras-chave: turismo acessível; unidade de conservação; deficiência.

\begin{abstract}
Tourism provides many benefits for both as destinations for people who practice it. However, not all people benefit from the activity, such as the disabled and persons with reduced mobility because they can not make use of spaces and tourist attractions due to the lack of adjustments. Thus, this research aims to discuss and analyze the infrastructure of Parque Nacional Serra da Capivara - PI, Cultural Patrimonial of Brazil, with regard to accessibility. To this end, we performed a literature search on the topic and a field survey during the months from July to September 2010, with direct observation of the area, data collection, interviews and informal conversations. It was felt then that the park has some infrastructure changes, mainly for wheelchair users, but superficially and in some cases incorrect.
\end{abstract} Keywords: accessible tourism; conservation unit; disabilities.

\footnotetext{
${ }^{1}$ Bacharel em Turismo - UESPI. Mestre em Desenvolvimento e Meio Ambiente - UFPI. Coordenadora do Eixo Hospitalidade, Lazer e Turismo e Docente do Curso de Guia de Turismo do Instituto Federal do Piauí (IFPI), Campus São Raimundo Nonato E-mail: stella@ifpi.edu.br.
} 


\section{Resumen}

Turismo ofrece muchos beneficios para ambos destinos como para las personas que lo practican. Sin embargo, no todas las personas se benefician de la actividad, tales como los discapacitados y las personas con movilidad reducida ya que no pueden hacer uso de los espacios y lugares de interés turístico debido a la falta de ajustes. Por lo tanto, esta búsqueda tiene como objetivo discutir y analizar la infraestructura del Parque Nacional de carpincho IP, Patrimonio Cultural de Brasil, con lo que se refiere a la accesibilidad. Con este fin, se realizó una búsqueda bibliográfica sobre el tema y un estudio de campo durante los meses de julio a septiembre de 2010, con la observación directa de la zona, la recolección de datos, entrevistas y conversaciones informales. Se consideró entonces que el parque cuenta con algunos cambios de infraestructura, principalmente para los usuarios de silla de ruedas, pero superficialmente y en algunos casos son correctos.

Palabras clave: turismo accesible; unidad de conservación; deficiencia.

\section{Introdução}

O turismo é uma das atividades econômicas com maior crescimento em todo mundo, e a cada ano aumenta o número de pessoas que viajam em busca de lazer, descanso, aventura, entre outros motivos. Segundo dados da Organização Mundial de Turismo - OMT (2011 apud MTUR, 2011), em 2003, foram registradas 696,6 milhões de chegadas de turistas em todo o mundo, e em 2010, esse número passou para 940 milhões, mostrando um aumento de 35\% no número de chegadas de turistas no mundo. Assim, viajar, independente do motivo, deve ser um direito de todas as pessoas.

Entretanto, percebe-se que um segmento específico da população, como as pessoas com deficiências ou mobilidade reduzida têm dificuldades para viajar ou usufruir completamente, de um determinado destino ou atrativo turístico, por não ser adaptado ou pelo fato dos profissionais que trabalham no setor, não terem treinamento e qualificação específicos.

O termo "pessoas com deficiência ou com necessidades especiais" é utilizado bastante na mídia e ainda provoca algumas discussões a seu respeito. Para Sá (2012), a denominação "pessoa com necessidades especiais" foi rapidamente difundida e assimilada, talvez, pela amplitude e abrangência de sua aplicabilidade. Conforme Sassaki (2002), o termo surgiu primeiramente para substituir "deficiência" por "necessidades especiais" e a partir de então 
originou-se a expressão "portadores de necessidades especiais". Posteriormente, esse termo passou a ter significado próprio sem substituir o nome "pessoas com deficiência".

Ainda conforme Sassaki (2002), o art. $5^{\circ}$ da Resolução CNE/CEB no 2, de 11/9/01, explica que as necessidades especiais decorrem de três situações, uma das quais envolvendo dificuldades vinculadas a deficiências e dificuldades não-vinculadas a uma causa orgânica. Deste modo, com a vigência desta Resolução, o termo "necessidades especiais" passou a ser um valor agregado tanto à pessoa com deficiência quanto a outras pessoas.

Para Sassaki (2002), o uso do termo "portador de deficiência" não é correto. Deve-se empregar o termo "pessoa com deficiência".

No Brasil, tornou-se bastante popular, acentuadamente entre 1986 e 1996, o uso do termo portador de deficiência (e suas flexões no feminino e no plural). Pessoas com deficiência vêm ponderando que elas não portam deficiência; que a deficiência que elas têm não é como coisas que às vezes portamos e às vezes não portamos (por exemplo, um documento de identidade, um guarda-chuva). (SASSAKI, 2002, p.7)

Entretanto, a legislação brasileira não reconhece ainda o termo "pessoa com deficiência", mas utiliza o termo "pessoa portadora de deficiência ou com mobilidade reduzida". Para os fins da Lei Federal de $n^{0}$ 10.098, de 19 de dezembro de 2000 (BRASIL, 2000b), é estabelecida a seguinte definição: "pessoa portadora de deficiência ou com mobilidade reduzida: a que temporária ou permanentemente tem limitada sua capacidade de relacionar-se com o meio e de utilizá-lo".

Conforme Sassaki (2010), o uso dos termos "pessoas com necessidades especiais" e "pessoas com deficiências" são corretos e devem ser utilizados, porém cada um na situação adequada. Ainda conforme o autor $(2010, \mathrm{p} .1)$,

(...) as necessidades especiais não são exclusivas de pessoas que têm deficiência. Mas, a deficiência pode ser uma das causas determinantes de necessidades especiais. Por exemplo: (a) Se uma pessoa tem pernas mecânicas e utiliza bengalas, as calçadas esburacadas e os pisos derrapantes podem causar necessidade especial para esta pessoa circular por essas ruas sem correr risco de levar um tombo. (b) Se uma pessoa anda em cadeira de rodas, os meio-fios sem rampa e as escadarias podem causar necessidade 
especial para esta pessoa locomover-se nessas ruas. (c) Se uma pessoa é cega, a falta de livros em braile pode causar necessidade especial para esta pessoa tomar conhecimento de textos em geral. [...] Muitas pessoas sem deficiência também podem deparar-se com necessidades especiais. [...] Não existe um segmento populacional composto por pessoas com necessidades especiais. O que existe é o segmento das pessoas com deficiência. Não podemos utilizar o termo "pessoas com necessidades especiais" como se estas pessoas formassem um segmento.

Assim, neste artigo será utilizado o termo "pessoas com deficiências ou mobilidade reduzida", englobando tanto as pessoas que efetivamente tem algum tipo de deficiência quanto às pessoas que, temporária ou permanente, tem limitada a sua capacidade de se relacionar com o meio e de utilizá-lo, não ocasionada por deficiência, como idosos, gestantes e obesos.

Apesar das dificuldades existentes, a acessibilidade no turismo começa a ser discutida no país, e desde 2004, foram estabelecidas normas gerais e critérios básicos para a promoção da acessibilidade das pessoas com deficiência ou com mobilidade reduzida e, que consequentemente, passaram a ter o direito, também, de fazer turismo. Deste modo, a atividade turística seria uma forma de inclusão social.

A partir deste pressuposto, o presente artigo é fundamental como fonte de referência sobre acessibilidade no turismo, e mostra um estudo de caso sobre o Parque Nacional Serra da Capivara - PI, um dos principais atrativos turísticos do Estado do Piauí e Patrimônio Cultural da Humanidade reconhecido pela UNESCO - Organização das Nações Unidas para a Educação, Ciência e Cultura, desde 1991 (UNESCO, 2012).

Existem poucos trabalhos sobre o tema, no Brasil, como o de Goulart (2007) que faz uma relação entre o turismo e esportes adaptados, o de Borges (2009) que aborda sobre a acessibilidade como fator de incremento do turismo em Formosa - GO, e o de Panosso e Panno (2010) que trata sobre a acessibilidade na cidade de São Paulo.

Assim, esta pesquisa objetivou analisar a infraestrutura física existente no PNSC bem como avaliar a qualificação dos condutores de visitantes para o atendimento de pessoas com deficiência ou mobilidade reduzida visando verificar a possibilidade de enquadrar o parque para prática do chamado "turismo acessível”. 


\section{Deficiência}

Pessoa com deficiência, de acordo com o Decreto Federal n. ${ }^{\circ}$ 914/1993 (Brasil, 1993), é "aquela que apresenta, em caráter permanente, perdas ou anomalias de sua estrutura ou função psicológica, fisiológica ou anatômica, que gerem incapacidade para o desempenho de atividades, dentro do padrão considerado normal para o ser humano”. Já as pessoas com mobilidade reduzida são aquelas que, não se enquadram no conceito de pessoa com deficiência, mas têm por qualquer motivo, dificuldade de movimentar-se permanente ou temporariamente, gerando redução efetiva de mobilidade, flexibilidade, coordenação motora e percepção, como os idosos, obesos e gestantes (MTUR, 2006).

Carmo (1991, p.12) comenta sobre a relação entre deficiência e incapacidade:

Segundo consenso internacionalmente existente, quando, em consequência de algum mal, o ser humano é vítima de um certo impedimento de ordem física, por exemplo, temos a instalação de uma deficiência. Essa deficiência poderá levar ou não a uma incapacidade, ou seja, a uma situação de desvantagem, de inferioridade.

Esta situação de desvantagem ou de inferioridade que as pessoas com deficiência enfrentam pode ser minimizada a partir da perspectiva de inclusão social. Segundo Sassaki (2005, p.3), inclusão social é:

(...) o processo pelo qual a sociedade se adapta para incluir, em seus sistemas sociais gerais, pessoas com necessidades especiais e, simultaneamente, estas se preparam para assumir seus papéis na sociedade. A inclusão social constitui então um processo bilateral no qual as pessoas, ainda excluídas, e a sociedade buscam, em parceria equacionar problemas, decidir sobre soluções e efetivar a equiparação de oportunidades para todos.

No Brasil, segundo dados do Censo (IBGE, 2010) existiam naquele ano cerca de 45 milhões de pessoas com deficiência no país, ou seja, 23,92\% da população. E no estado do Piauí, ainda de acordo com esses dados, $27,59 \%$ da população apresenta algum tipo de deficiência.

Segundo Borges (2009) diversas nomenclaturas que já foram empregadas para designar pessoas com deficiência, como: “incapazes", "defeituosos", "pessoas portadoras de 
deficiência", entre outros. Observa, ainda, que para que se obtenha uma sociedade mais inclusiva é preciso atenção quanto ao vocabulário empregado, já que através da linguagem expressam-se preconceitos e discriminações.

Sassaki (2005) afirma que já é consensual o emprego da expressão "pessoas com deficiência", tanto em manifestações orais quanto escritas. Borges (2009) ainda comenta que o termo foi utilizado na Convenção sobre os Direitos das Pessoas com Deficiência, da Assembleia Geral das Nações Unidas, em 2006.

Conforme a nomenclatura da Organização Mundial da Saúde (OMS apud MTUR, 2009a), existem diversos tipos de deficiência. São elas:

- indivíduo com deficiência intelectual ou mental: é aquele que mostra funcionamento intelectual significativamente inferior à média, com manifestação antes dos dezoitos anos, e limitações associadas a duas ou mais áreas de habilidades adaptativas, como a comunicação, o cuidado pessoal, a utilização dos recursos da comunicação, saúde e segurança, entre outros;

- indivíduo com paralisia cerebral: é aquele que tem uma lesão de uma ou mais áreas do sistema nervoso central, o que pode causar alterações psicomotoras, podendo ou não provocar a deficiência intelectual;

- indivíduo com deficiência física: é aquele com alteração completa ou parcial de um ou mais segmentos do corpo, ocasionando o comprometimento da função física, apresentando-se sob diversas formas, como a paraplegia, tetraplegia e amputação;

- indivíduo com deficiência auditiva: o surdo, ou seja, aquele que perdeu a capacidade de ouvir, seja perda bilateral, parcial ou total, de quarenta e um decibéis $(\mathrm{dB})$ ou mais, aferida por audiograma nas freqüências de $500 \mathrm{~Hz}, 1.000 \mathrm{~Hz}, 2.000 \mathrm{~Hz}$ e $3.000 \mathrm{~Hz}$;

- indivíduo com deficiência visual: o cego, ou seja, aquele cuja acuidade visual é igual ou menor que 0,05 no melhor olho, com a melhor correção óptica; ou aquele com baixa visão, com acuidade visual entre 0,3 e 0,05 no melhor olho, com a melhor correção óptica;

- indivíduo surdo e cego: é aquele com perda substancial de visão e audição;

- indivíduo com deficiências múltiplas: é aquele com associação de duas ou mais deficiências. 
Assim, nota-se que há uma grande variedade de tipos de deficiência, e que consequentemente exige diversos tipos de adaptações, o que torna o acesso dessas pessoas aos mais variados ambiente bastante complicado.

\section{Turismo Acessível}

As pessoas com deficiência ou mobilidade reduzida têm direito a acesso a qualquer lugar, inclusive para a prática do lazer e turismo. Segundo a Resolução nº48/96, de 20/12/93, sobre as Normas sobre Equiparação de Oportunidades para Pessoas com Deficiência, da Organização das Nações Unidas (ONU, 1993, p.1),

Os Países-Membros devem tomar medidas para garantir que pessoas com deficiência tenham oportunidades iguais para recreação e esportes.

Os Países-Membros devem iniciar medidas para tornar acessíveis às pessoas com deficiência os locais de recreação e esportes, hotéis, praias, estádios, quadras esportivas etc. Tais medidas devem abranger a participação, a informação e os programas de treinamento e o apoio ao pessoal dos programas de recreação e esportes, incluindo projetos para desenvolver métodos de acessibilidade.

As autoridades de turismo, as agências de viagens, os hotéis, as organizações voluntárias e outras entidades envolvidas em organizar atividades recreativas ou oportunidades de viagem devem oferecer seus serviços a todas as pessoas, levando em consideração as necessidades especiais das pessoas com deficiência. Deve ser provido um adequado treinamento para ajudar neste processo.

Entretanto, cumprir esses deveres não é uma tarefa fácil. O Brasil, como país-membro da ONU, também deve seguir esta Resolução. Para tanto, desde a divulgação do Plano Nacional do Turismo 2007/2010 - Uma viagem de inclusão, elaborado pelo Ministério do Turismo (MTur), a busca pela promoção de um turismo mais acessível tornou-se prioridade pelo Governo Federal brasileiro (MTUR, 2007).

Conforme este plano, um dos objetivos do MTur é fazer do turismo um indutor da inclusão social tanto com a criação de novos postos de trabalho, ocupação e renda, quanto pelo consumo, com a captação de novos turistas no mercado interno. Entretanto, percebeu-se, apenas, que desde 2007 a 2010 houve somente a estruturação de destinos turísticos adaptados, 
como Socorro - SP, e a divulgação de manuais e cartilhas sobre o assunto. Não existem dados que comprovem, de fato, que o turismo tornou-se um indutor da inclusão social.

Segundo Sassaki (2003), o processo de inclusão social no turismo ocorre quando a sociedade é ajudada a modificar seus sistemas de lazer e turismo para que todas as pessoas, com ou sem deficiência, possam participar juntas e ativamente de suas atividades nos mesmos locais, desfrutando de momentos de lazer em ambientes comuns.

Assim, promover o turismo acessível é dar condições para as pessoas com deficiência e mobilidade reduzida a utilizar, com segurança e autonomia, todos os espaços e equipamentos turísticos, como qualquer pessoa dita normal.

As maiores dificuldades encontradas por este grupo de pessoas estão nas barreiras. Estas podem ser conceituadas, conforme o Decreto $n^{0}$ 5.296/2004 (BRASIL, 2004, p.2) como: "qualquer entrave ou obstáculo que limite ou impeça o acesso, a liberdade de movimento, a circulação com segurança e a possibilidade de as pessoas se comunicarem ou terem acesso à informação". Estas barreiras podem ser urbanísticas (existentes nas vias e espaços de uso público), nas edificações (localizadas no entorno e interior das edificações de uso público e coletivo e nas suas áreas internas), nos transportes (existentes nos serviços de transportes), das informações e comunicações (qualquer entrave ou obstáculo que dificulte ou impossibilite a expressão ou recebimento de mensagens ou o acesso à informação).

Para Sassaki (2003), existem seis tipos diferentes de barreiras encontradas nos espaços turísticos. São elas: barreiras arquitetônicas (não permite a acessibilidade da pessoa com dificuldade de locomoção), comunicacional (a linguagem verbal ou visual utilizada não alcança todas as pessoas), atitudinal (atitude preconceituosa), metodológica (métodos de ensino, trabalho e lazer homogêneos), instrumental (instrumentos utilizados para trabalhar, brincar que não atendem as limitações), programática (leis, portarias, regulamentos e políticas que perpetuam a exclusão). Ainda conforme o autor (2003, p. 35), "muitas pessoas com deficiência não podem ter acesso aos logradouros turísticos e aos empregos disponíveis no setor, porque existem, nos ambientes de lazer, recreação e turismo do país, os seis tipos de barreiras".

Estas barreiras estão presentes não só nas grandes cidades, mas também nos atrativos turísticos, que, em sua maioria, não possuem adaptações simples, como o acesso com rampas 
e placas informativas. É necessário, portanto, que haja a promoção da acessibilidade, que beneficiaria, primeiramente, à população local e em seguida aos turistas.

Deste modo, promover a acessibilidade é dar:

(...) condição para utilização, com segurança e autonomia, total ou assistida, dos espaços, mobiliários e equipamentos urbanos, das edificações, dos serviços de transporte e dos dispositivos, sistemas e meios de comunicação e informação, por pessoa com deficiência ou com mobilidade reduzida (MTUR, 2009a, p. 19).

Assim, o termo acessível implica tanto acessibilidade física como de comunicação, e isso se aplica ao turismo. Qualquer estabelecimento e espaço, seja ele turístico ou não, deve ser acessível tanto para as pessoas com deficiência como para as que não têm. Os espaços devem ser projetados, seguindo o chamado "desenho universal", de acordo Decreto Federal 5.296 em seu artigo $8^{\circ}$, inciso IX, ou seja, construídos para atender simultaneamente todas as pessoas, com diferentes características antropométricas e sensoriais, de forma autônoma, segura e confortável, constituindo-se nos elementos ou soluções que compõem a acessibilidade (RULLI, 2002). Aguirre (2003) comenta que para que estes locais se tornem acessíveis, alguns pontos devem ser observados nos:

- locais para informação e comercialização: observar os acessos (se há estacionamento exclusivo para os deficientes, se há desníveis, o tamanho das portas); observar como acontece a circulação interior; observar o mobiliário (altura de mesas, balcões e expositores); observar se há informação e sinalização acessível;

- locais para alojamento: analisar os acessos (estacionamento, percurso até o edifício, zona de manobra, desníveis e portas de entrada e saída), a circulação no interior (passagens e percursos, zonas de manobra, elevadores e revestimentos), os dormitórios, os banheiros, o mobiliário (mesa e cadeiras, camas e armários), as instalações (telefone adaptados, televisão, altura de interruptores de iluminação e temperatura), informação e sinalização acessível;

- locais de restauração e locais de lazer e recreação: semelhantes aos anteriores.

A norma NBR9050 da Associação Brasileira de Normas Técnicas - ABNT (2004, p.2) afirma que acessibilidade é a "possibilidade e condição de alcance, percepção e entendimento para a 
utilização com segurança e autonomia de edificações, espaço, mobiliário, equipamento urbano e elementos". A norma ainda determina que:

(...) todos os espaços, edificações, mobiliários e equipamentos urbanos que vierem a ser projetados, construídos, montados ou implantados, bem como as reformas e ampliações de edificações e equipamentos urbanos, devem atender ao disposto nesta Norma para serem considerados acessíveis (ABNT, 2004, p.1).

Percebe-se, portanto, que existem muitos pontos a serem observados, corrigidos e adaptados para torná-los acessíveis. Isso requer um investimento alto na compra de equipamentos específicos e na construção das adaptações necessárias. Todavia, pelo número de deficientes que buscam equipamentos ou atrativos turísticos ser baixo, muitas empresas e destinos turísticos preferem ignorar este segmento, ou se dizem "adaptados", mesmo que essa adaptação se dê de uma forma incompleta ou superficial, ou seja, adaptando apenas alguns espaços ou mobiliários.

Outro problema para a promoção do turismo acessível está na qualificação e treinamento dos profissionais que trabalham no setor. Estes são responsáveis pelo atendimento direto à pessoa com deficiência ou mobilidade reduzida; sejam eles: recepcionistas, garçons, condutores e guias de turismo, motoristas, entre outros. Assim, a qualificação desses profissionais seria um diferencial para os atrativos, além de ser algo necessário e obrigatório, segundo a NBR 15599 (ABNT, 2008), que diz que os serviços de turismo devem prover treinamento de seus funcionários para melhor atender pessoas com deficiências.

Para Borges (2009, p.24), “o turismo acessível não deve ser entendido como apenas um direito social, mas como uma interessante oportunidade de mercado e de negócio para o setor". Ao se desenvolver um turismo adaptado para qualquer pessoa, atingirá um segmento que tem o desejo e a vontade de viajar. No Brasil, ainda não se tem dados sobre o número de turistas deficientes ou sobre o número de pessoas com deficiência que gostariam de viajar.

Segundo Butler e Jones (2003), a população com deficiência raramente aparece em estimativas ou previsões relacionadas ao turismo como um segmento em potencial, apesar de ser um grupo grande e que tende a crescer com o aumento da expectativa de vida. 
Para Buhalis e Eichhorn (2005), a demanda por acessibilidade na Europa é de mais de 127 milhões de pessoas, sendo que 70\% delas representam um potencial mercado de consumo de produtos turísticos. Ao comparar esta mesma proporção com os dados brasileiros, que até o ano 2010 tinha mais de 45 milhões de deficientes (IBGE, 2010), obtém-se um número de 31 milhões de turistas em potencial, o que é um número bastante significativo.

Segundo o MTur (2009b), é preciso fazer um mapeamento da acessibilidade no município ao qual pretende-se desenvolver o turismo acessível. Esse mapeamento,

(...) tem por objetivo analisar, de forma geral, os aspectos de acessibilidade turística às pessoas com deficiência ou mobilidade reduzida, envolvendo visitas e observações técnicas dos equipamentos e edificações públicos e seu mobiliário urbano, assim como das instalações e serviços dos estabelecimentos privados e dos principais pontos turísticos locais.

Ainda conforme o MTur (2009b), por meio do mapeamento é possível incentivar a acessibilidade e adequar ambientes; sensibilizar e conscientizar a comunidade local e os turistas sobre a inclusão de pessoas com deficiência; e contribuir para a elaboração de políticas públicas, planos e projetos de acessibilidade.

Após esse mapeamento, devem-se realizar as adaptações necessárias de equipamentos e instalações, adequar o sistema de transporte local, melhorar a comunicação e sinalização, qualificar e treinar os profissionais que trabalham no setor turístico, elaborar roteiros e produtos turísticos adaptados e desenvolver a promoção e comercialização dos mesmos. Essas são as principais etapas para tornar um destino turístico adaptado.

O MTur (2009c), com base no Decreto Federal n. ${ }^{\circ}$ 914/1993 e nas normas da ABNT, NBR 9050:2004, enumera algumas condições gerais de acessibilidade em organizações turísticas:

- calçadas: parte integrante da via pública deve possuir largura mínima de 1,20 m, inclinação transversal de $3 \%$ e ter superfície feita com material regular, firme e estável; as faixas de pedestres devem ser pintadas e iluminadas, e a implantação de rampas de acesso no nível da travessia é fundamental;

- estacionamento: as vagas reservadas para veículos que conduzem ou são conduzidos por pessoas com deficiência devem ser garantidas junto às vias públicas, permitindo o acesso a 
qualquer lugar; devem ser sinalizadas com o Símbolo Internacional de Acesso (SIA), na forma horizontal e vertical; toda vaga deve ter uma área de embarque e desembarque de, no mínimo, 1,20m além da dimensão da vaga - em pelo menos um dos lados; o piso deve ser regular, firme e antiderrapante e o percurso entre o estacionamento de veículos, quando houver, e a entrada do estabelecimento deve ser acessível;

- acesso à entrada e ao interior dos estabelecimentos: deve estar livre de obstáculos; desnível superior a $15 \mathrm{~mm}$ deve ser tratado como degrau e deve ser substituído por rampa com inclinação adequada para o acesso de usuários de cadeira de rodas; quando não houver espaço suficiente para a construção de rampas, pode ser utilizado equipamento eletromecânico, como plataforma elevatória ou elevador de uso específico para pessoas com deficiência ou mobilidade reduzida; deve-se criar facilidade no acesso à elevadores, escadas rolantes, telefone público acessível e sanitários adaptados; todos os acessos para pessoas com deficiência devem ser sinalizados com o SIA; os balcões de atendimentos devem ter pelo menos uma parte da superfície, com extensão de no mínimo $0,90 \mathrm{~m}$, com altura de, no máximo, 0,90m do piso; deve ser garantido a aproximação frontal da pessoa usuária de cadeira de rodas e os objetos expostos para alcance devem estar na altura máxima de 1,20 m;

- sanitários: deve-se ter pelo menos um sanitário por pavimento adaptado para pessoas com deficiência ou mobilidade reduzida.

De acordo com a NBR 9050:2004 (ABNT, 2004, p. 87), "sempre que os parques, praças e locais turísticos admitirem pavimentação, mobiliário ou equipamentos edificados ou montados, estes devem ser acessíveis" e "nos locais onde as características ambientais sejam legalmente preservadas, deve-se buscar o máximo grau de acessibilidade com mínima intervenção no meio ambiente". Deste modo, todos os locais turísticos estão obrigados às adaptações legais exigidas sendo também classificados como edificações de uso coletivo.

Na Norma NBR 9050:2004 (ABNT, 2004) e na Lei Geral do Turismo (Brasil, 2008) não há uma definição de "local turístico", mas entende-se como qualquer local ou espaço que receba e atraia visitantes e turistas.

Nesse sentido, o foco deste trabalho, o Parque Nacional Serra da Capivara - PI, que é uma Unidade de Conservação, é também um parque e um local turístico (por atrair visitantes), devendo, portanto, promover as adaptações para esse tipo de espaço. 
Deste modo, por ser um local público, apesar de ter acesso controlado, se fazem obrigatórias as adaptações padrões, ou poderão se desenvolver materiais sensoriais adaptados para atendimento de pessoas com deficiências sensoriais (visão e audição), tais como maquetes, brinquedos, pranchas táteis, placas informativas em Braille, jogos e réplicas.

Ainda segundo NBR 9050:2004 (ABNT, 2004), os locais onde há a prática de atividades ao ar livre, como é o caso do Parque, devem contar com acessibilidade no embarque e desembarque dos atrativos. É preciso, também, prestar atenção se nas trilhas, não há elementos da vegetação, como galhos e arbustos, nas rotas de circulação.

Os locais adaptados para o turismo devem ter diversas formas de comunicação e sinalização para facilitar a utilização dos mesmos pelos deficientes ou com mobilidade reduzida. Como comentado anteriormente, para indicação de acessos, escadas, elevadores, equipamentos, telefones e sanitários acessíveis deve-se utilizar o SIA, seguindo os padrões internacionais de cores e proporções (pictograma branco sobre fundo azul ref. Munsell 10B5/10 ou Pantone 2925 C) (MTUR, 2009c).

Existem também as sinalizações táteis: caracteres; figuras em relevo e Braille. Estes são sistemas utilizados por pessoas com deficiência visual. O Braille é um sistema de leitura tátil e escrita para pessoa cega, que permite a compreensão do espaço físico.

Há também as sinalizações, comumente empregadas no piso (com finalidade de alerta ou direcionamento), em placas de identificação de ambientes, sanitários, porta e painel de controle de elevadores, mapas táteis, cardápios, entre outros (MTUR, 2009c). Segundo o Instituto Benjamin Constant (2001), as pessoas com baixa visão podem ter seu resíduo visual melhorado através da utilização dos seguintes recursos: lupas, telessistemas, tiposcópio, iluminação adicional, entre outros.

Assim, estes tipos de recursos, também, podem ser utilizados na identificação de atrativos turísticos ou de elementos que devem ser destacados durante uma trilha. Por exemplo: os caminhos de uma trilha podem ser seguidos com o auxílio de uma corda, e em pontos específicos podem-se colocar nós e placas informativas em Braille, bem como em letras grandes, como recomendado pela ABNT (2004), para indicar a presença de uma espécie animal ou vegetal importante da região. Poder-se-ia disponibilizar lupas para facilitar a observação dos deficientes visuais com baixa acuidade visual. 
Ainda em relação à comunicação e sinalização, podem ser instalados equipamentos sonoros com gravações para orientar e informar os turistas deficientes visuais. E para atender os deficientes auditivos, é recomendável a presença um profissional intérprete da Língua Brasileira de Sinais - LIBRAS ou capacitar os profissionais que já atuam no setor turístico para este fim.

\section{Metodologia}

Inicialmente, fez-se uma pesquisa bibliográfica sobre o tema e, em seguida, a coleta dos dados através da realização de entrevistas e pesquisa de campo no Parque Nacional Serra da Capivara.

A pesquisa de campo foi realizada durante os meses de julho a setembro de 2010 e contou com o auxílio da Associação de Condutores de Visitantes Ecoturísticos do Parque Nacional Serra da Capivara - ACOVESP. Consistiu na observação direta da infraestrutura do Parque (seus sítios arqueológicos principais) e na realização de medições, com o uso de uma trena, para identificar se o PNSC realmente está adaptado para receber visitantes com deficiência ou mobilidade reduzida, sendo, assim um destino para o desenvolvimento do turismo acessível.

Esta observação direta da infraestrutura do PNSC foi baseada na norma NBR9050 da ABNT (2004), que estabelece critérios e parâmetros técnicos a serem observados quando do projeto, construção, instalação e adaptação de edificações, mobiliário, espaços e equipamentos urbanos às condições de acessibilidade. Esta Norma descreve, também, como devem ser as adaptações em parques, locais turísticos e ambientes naturais, e determina dimensões, larguras e alturas de mobiliários e edificações, como por exemplo: largura para deslocamento em linha reta de pessoas em cadeira de rodas e área de manobras; patamares das rampas; degraus e escadas fixas; altura de corrimãos e guarda-corpos; entre outros.

Foram visitados seis circuitos de visitação do Parque: Desfiladeiro da Capivara, Veadinhos Azuis, Jurubeba, Boqueirão da Pedra Furada, Sítio do Meio e Serra Vermelha; totalizando 52 sítios arqueológicos visitados, ou seja, 41,26\% dos sítios abertos à visitação.

Essa pesquisa contou, também, com a aplicação de entrevistas e conversas informais com a Chefe do Escritório Técnico do Instituto do Patrimônio Histórico e Artístico Nacional - IPHAN de São Raimundo Nonato, o Chefe do Escritório do Instituto Chico Mendes para Conservação da 
Biodiversidade - ICMBio de São Raimundo Nonato, com a Chefe do Setor de Engenharia e Arquitetura da Fundação Museu do Homem Americano - FUMDHAM e com condutores de visitantes do Parque. As entrevistas tiveram como objetivo coletar informações sobre as estruturas de adaptação implantadas no PNSC, possíveis novas adaptações, os dados de visitação do mesmo e sobre a experiência dos condutores com visitantes deficientes ou com mobilidade reduzida.

Durante o trabalho de campo, constatou-se que no PNSC não há um livro de registro de visitantes com dados sobre o perfil dos mesmos. Há, somente, um registro em termos quantitativos, devido ao pagamento do ingresso de entrada no Parque, e foram estes dados os fornecidos pelo ICMBio. Assim, os dados referentes a visitas de pessoas com algum tipo de deficiência foram obtidos através de entrevistas com os condutores, que sempre acompanham os visitantes, já que não é permitida a entrada no Parque sem o acompanhamento desses profissionais. Deste modo, detectou-se se os condutores já tiveram contato com pessoas com deficiências ou mobilidade reduzida, durante as visitas ao PNSC.

\section{O Parque Nacional Serra da Capivara - PI}

O Parque Nacional Serra da Capivara - PNSC está localizado ao sul do estado do Piauí, a cerca de $560 \mathrm{~km}$ da capital, Teresina. O Parque foi criado em 05 de junho de 1979, pelo Decreto $\mathrm{n}^{\circ} .83 .548$, com uma área de 100.000 ha, ampliado para 129.140 ha pelo Decreto de 99.193, de 12 de março de 1990, com um perímetro de $214 \mathrm{~km}$. Atualmente, compreende áreas dos municípios de São Raimundo Nonato, Brejo do Piauí, Coronel José Dias e João Costa (ARAÚJO, 2006).

Em 1991, o Parque foi reconhecido pela UNESCO como Patrimônio Cultural da Humanidade e em 1993 foi tombado como Patrimônio Cultural Material pelo IPHAN, com registro no Livro do Tombo Arqueológico, Etnográfico e Paisagístico. Isto mostra o reconhecimento da importância do Parque tanto no contexto local, nacional e internacional.

De acordo com a FUMDHAM (2010), na região do PNSC estão cadastrados 1223 sítios com arte rupestre, sendo 922 sítios com pinturas, 218 com pinturas e gravuras e 83 somente com gravuras. O sítio arqueológico é um local no qual homens deixaram algum tipo de vestígio de suas atividades, como uma ferramenta de pedra, uma fogueira na qual assaram sua comida, uma pintura, uma sepultura, a simples marca de seus passos, entre outros. Estes sítios estão localizados num contexto geológico diversificado, que retrata o processo de formação da 
região há 240 milhões de anos com o levantamento do fundo do mar. Deste modo, os vestígios mais antigos são os que estão mais no fundo, pois ao longo dos anos, novos vestígios caíram, novas camadas de sedimento se formaram e, o sítio, vai apresentando uma maior espessura de camadas arqueológicas. Estes vestígios são dos primeiros povos que viveram na América.

Segundo a FUMDHAM (1998), o Parque foi criado devido a diversos fatores, como:

- cultural: centenas de sítios arqueológicos com pinturas e gravuras rupestres, que demonstram vestígios da presença humana na região há mais de 50.000 anos, além de artefatos como ossos, cerâmicas e restos de fogueira. A maioria dos sítios apresentam pinturas rupestres e os demais se destinam a acampamentos ou aldeias de caçadores-coletores, ceramistas-agricultores, ocupações em grutas ou abrigos, sítios funerários e sítios arqueopaleontológicos;

- ambiental: a região é fronteiriça entre as formações geológicas da bacia sedimentar Maranhão-Piauí e a depressão periférica do rio São Francisco, com paisagens variadas nas serras, vales e planície, vegetação de caatinga, configurando como o único Parque Nacional brasileiro em que a área total está situada no domínio da caatinga, abrigando fauna e flora específicas, pouco estudadas e de importante diversidade biológica;

- turístico: possui paisagens naturais surpreendentes, manifestando potencial para o turismo cultural e ecológico, enquanto uma alternativa de desenvolvimento.

Conforme pesquisa da FUMDHAM (2010), a região do Parque foi coberta, entre 440 e 360 milhões de anos atrás, pelo mar Siluriano-Devoniano, limitado ao sul pelo escudo cristalino do Pré-Cambriano, e por volta de 225-210 milhões de anos atrás, durante o período Triássico, um movimento tectônico de grande porte, iniciando a abertura do Atlântico sul, fez levantar o fundo do mar, criando a serra, formada por rochas sedimentares, arenitos e conglomerados. Por este motivo que a atual paisagem do PNSC é composta por planaltos ou chapadas, morros, serras, serrotes e planícies, formados por duas grandes formações geológicas, a Bacia Sedimentar Piauí-Maranhão e a Depressão do Médio São Francisco.

Esta Bacia foi, portanto, uma depressão, isto é, uma parte do relevo coberta pelo mar, que foi sendo preenchida com sedimentos, retirados, pela erosão das áreas mais altas do continente, e 
transportados pelos rios, ventos e chuvas. Nas áreas planas aparecem as chapadas e nas bordas do planalto aparecem as cuestas (localmente chamada de serra) e canyons (resultado de processos erosivos). Já a formação geológica da Depressão Periférica do médio São Francisco, é a área mais baixa da região, face ao planalto.

De acordo com Arruda (1997), a temperatura média anual da região é de $28{ }^{\circ} \mathrm{C}$, sendo a máxima de $35{ }^{\circ} \mathrm{C}$ e a mínima de $12{ }^{\circ} \mathrm{C}$. E segundo Pellerin (1991 apud OLIVEIRA FILHO, 2007, p. 104), a área do PNSC estende-se por três conjuntos geomorfológicos, em que redes hidrográficas apresentam fisionomias diferenciadas:

- planaltos areníticos (chapadas) do reverso da Cuesta, que possui rede hidrográfica larga com vales paralelos orientados no sentido norte-sul (riachos da Serra Branca, Boqueirão e Bom Jesus);

- zona cuesta (Serra Nova, Capivara, Talhada), situada no reverso arenítico duro, com rede de canyons dendriformes, que são rapidamente inundados durante as chuvas intensas;

- região do pedimento, localizada ao sul e a leste da Serra da Capivara constitui-se numa vasta planície, cujos vales suaves que compõem a rede hidrográfica, convergem para a calha do rio Piauí.

Os trabalhos de preservação do PNSC e dos sítios arqueológicos consistem em uma ação conjunta do Instituto Chico Mendes de Conservação da Biodiversidade - ICMBio, o IPHAN e da FUMDHAM. O Parque conta, ainda, com apoio financeiro de outras instituições, como a Petrobrás, Grupo Abengoa e Banco BNDES.

O Parque dispõe de infraestrutura para visitação, com um total de 126 sítios arqueológicos abertos ao público; passarelas e guarda-corpo; 30 guaritas de entrada com guarda permanente, sendo 9 abertas ao público, rádio de comunicação e toaletes; um Centro de Visitantes com auditório com capacidade para 50 pessoas, exposição de fósseis de animais pré-históricos da região, loja de souvenirs, e uma lanchonete; $300 \mathrm{~km}$ de trilhas de piçarra, com caneletas para escoamento de água, e, em sua maioria, liberadas para carros pequenos; mais de $100 \mathrm{~km}$ de trilhas para pedestres; placas de sinalização e placas interpretativas (em alguns sítios); e cerca de 16 sítios são considerados, pela FUMDHAM e pelo IPHAN, adaptados para deficientes físicos ou com mobilidade reduzida (FUMDHAM, 2010). A estrutura física para visitação do 
PNSC é considerada uma das melhores do país, por revistas e guias do segmento turístico, como Guia Quatro Rodas e Revista Viagem e Turismo.

O Parque é uma Unidade de Conservação - UC do tipo proteção integral, ou uso indireto, pertencente à categoria Parque Nacional. Este tipo de UC tem como objetivo a preservação dos ecossistemas naturais de grande relevância ecológica e beleza cênica, possibilitando a realização de pesquisas científicas e o desenvolvimento de atividades de educação e interpretação ambiental, de recreação em contato com a natureza e de turismo ecológico (BRASIL, 2000b) Nos Parques Nacionais é permitida a visitação pública e o incentivo de atividades turísticas, e isto não é diferente no Parque Nacional Serra da Capivara, que desde 2006 até setembro de 2010 já recebeu mais de 50.000 visitantes, entre pagantes e nãopagantes, segundo dados registrados pelo ICMBio, obtidos em pesquisa de campo.

O PNSC faz parte de um dos sete polos de desenvolvimento do turismo do Estado do Piauí, o Polo das Origens, que o tem como principal atrativo turístico (PIAUÍ, 2011). É, também, um dos 65 destinos indutores do turismo no país (MTUR, 2008). Isso mostra a importância do Parque no âmbito turístico, tanto local quanto nacional.

Para se ter acesso ao Parque é necessária a contração de um condutor de visitantes. Na cidade de São Raimundo Nonato - PI, há a Associação de Condutores de Visitantes Ecoturísticos do Parque Nacional Serra da Capivara - ACOVESP, criada em 1999. Segundo informações obtidas pela Associação, através de entrevista informal, a ACOVESP, em 2010, contava com 51 associados e 30 condutores ativos que absorviam 100\% da demanda do Parque. Ainda, conforme a Associação, os condutores têm cursos de condução de visitantes, ministrados pela FUMDHAM e do ICMBio.

\section{Acessibilidade no Parque Nacional Serra da Capivara - PI}

O Circuito do Desfiladeiro da Capivara é composto por onze sítios arqueológicos. São eles: Toca Nova da Entrada, Toca do Pajaú, Toca Entrada do Pajaú, Toca do Inferno, Toca do Barro, Toca do Paraguaio, Toca do Baixão da Vaca, Toca da Entrada do Baixão da Vaca, Toca Grande da Areia, Toca Pequena da Areia e Toca do Mapa do Desfiladeiro. Destes, nenhum é adaptado. 
O Circuito dos Veadinhos Azuis tem oito sítios, porém nenhum adaptado. São eles: Toca do Fundo do Baixão da Vaca I, II e III, Toca da Gameleira do Baixão da Vaca, Toca dos Veadinhos Azuis, Toca do Neguinho Só, Toca do Paredão dos Veados e Toca do Deitado.

O Circuito Boqueirão da Pedra Furada é o mais tradicional de visitação. Possui catorze sítios. São eles: Boqueirão da Pedra Furada, Pedra Furada, Alto da Pedra Furada, Baixão das Mulheres, Toca do Carlindo I, II e III, Toca do Boqueirão do Pedro Rodrigues, Toca da Fumaça I, II e III, Toca do Cajueiro, Toca do Arame do Sansão, Toca do Fundo do Baixão da Pedra Furada. Destes, sete são parcialmente adaptados para cadeirantes.

De acordo com observação de campo e medição, o Boqueirão da Pedra Furada, a Toca do Arame do Sansão e a Toca do Fundo do Baixão da Pedra Furada possuem acesso pavimentado com cimento desde o estacionamento (com exceção de um trecho de aproximadamente 5 metros do Centro de Visitantes à rampa do Boqueirão da Pedra Furada Figura 1), rampas de acesso aos sítios e espaço para manobras das cadeiras. Entretanto, por meio de medições, constatou-se que a largura da calçada, em alguns trechos, é inferior a 1,20m (largura mínima de acordo com a norma da ABNT), como na Toca do Fundo do Baixão da Pedra Furada, que a largura é de 0,90m e que o espaço de manobras também é inferior ao necessário que é de 1,50m x 1,50m, como no Boqueirão da Pedra Furada (Figura 2). O acesso à Toca do Arame do Sansão conta com uma calçada de 1,30m com extensão de 200m sob árvores de grande porte. Já a Toca do Carlindo II, Toca da Fumaça I e III e Toca do Cajueiro só possuem estruturas de adaptação no local do sítio, como pavimentação de cimento e rampas com largura média de $1,10 \mathrm{~m}$. Os demais sítios do Circuito Boqueirão da Pedra Furada não são adaptados para deficientes. 


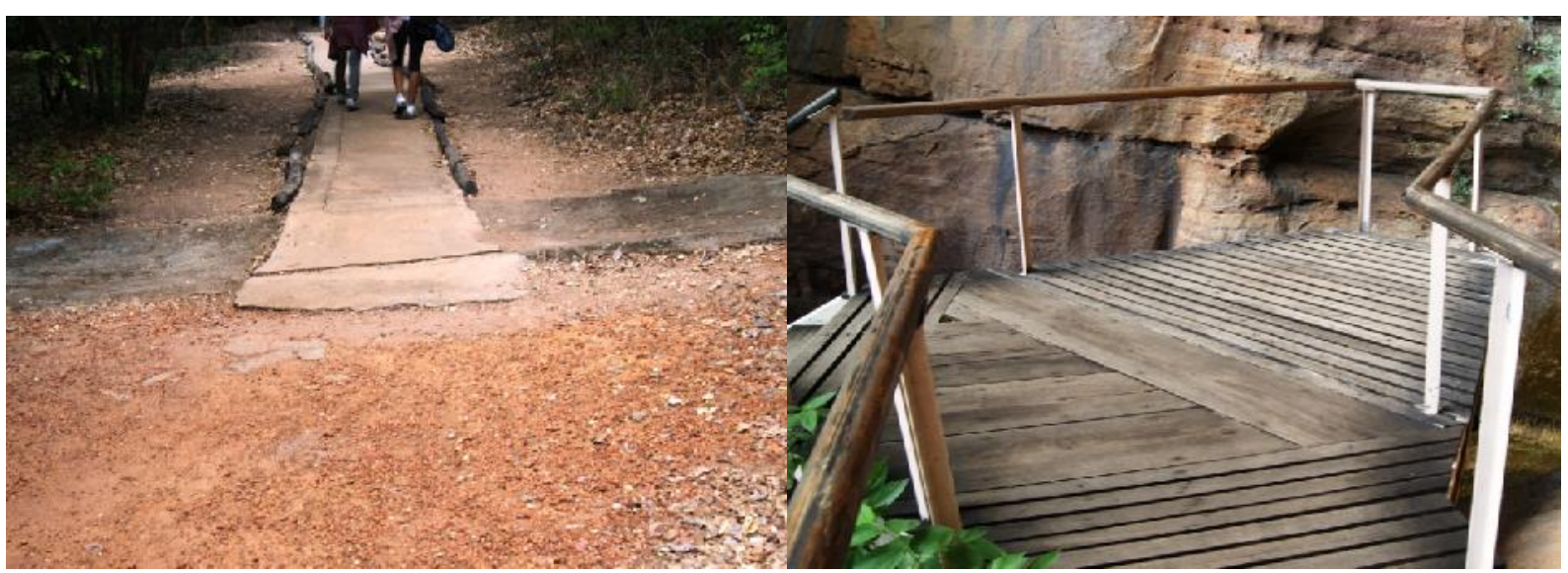

Figura 1: Acesso não pavimentado da trilha Boqueirão da Pedra Furada (A); área de manobras da passarela do Boqueirão da Pedra Furada (B) Fonte: arquivo pessoal (set./2010).

O Circuito do Sítio do Meio é composto por seis sítios arqueológicos. São eles: Toca do Sítio do Meio, Toca do Caldeirão do Sítio do Meio, Toca da Escadinha do Sítio do Meio, Toca do Sítio do Meio de Cá, Toca da Guabiraba e Toca da Jurema da Ponta da Serra. Destes, somente a Toca do Sítio do Meio é adaptada, porém, só em uma parte do sítio. Esse local possui acesso pavimentado com cimento desde o local de estacionamento, com rampas de acesso de largura superior a 1,20m (medição in loco), porém o local para manobras das cadeiras de rodas não possui a largura mínima, que é de $1,50 \mathrm{~m}$ por $1,20 \mathrm{~m}$, para uma rotação de $180^{\circ}$ (ABNT, 2004). Como é um circuito linear, o cadeirante retorna pelo mesmo local que começou a visitação nas passarelas, não conseguindo fazer a manobra de rotação.

O Circuito da Jurubeba possui dez sítios abertos à visitação. São eles: Toca do Bonecão, Toca do Zé Luiz, Toca da Ema do Sítio do Brás I e II, Toca do Caminho da Ema, Toca do Exú, Toca da Roça do Sítio do Brás I e II, Toca do Mangueira e Casa do Alexandre. Destes, somente cinco possuem adaptações para deficientes físicos. A Toca da Ema do Sítio do Brás II (Figura 2), Toca da Roça do Sítio do Brás I e II e Toca do Mangueira possuem acesso pavimentado desde o estacionamento e rampas de acesso, com média de 1,20m de largura (medição in loco). Já a Casa do Alexandre só tem acesso pavimentado até a sua porta, pois não é permitida a entrada neste local, que é um exemplo da utilização dos sítios arqueológicos como moradia. 


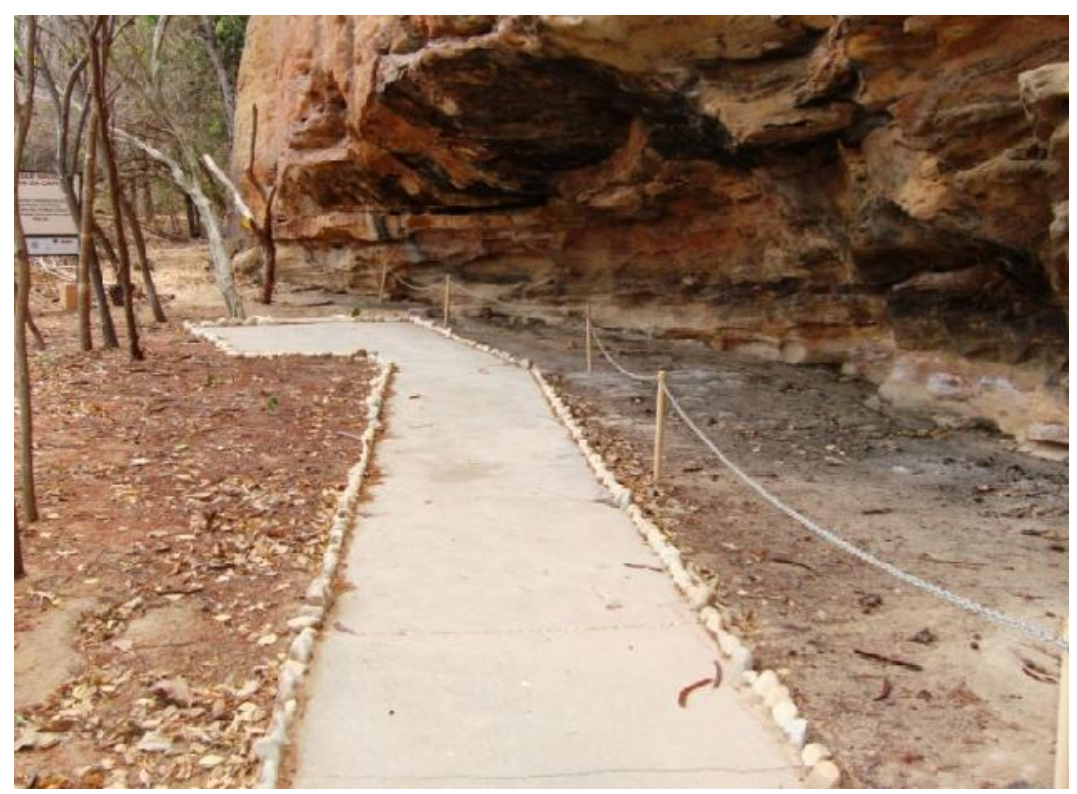

Figura 2: Calçada pavimentada e espaço de manobras da Toca da Ema do Sítio do Brás II Fonte: arquivo pessoal (set./2010).

O Circuito da Serra Vermelha é composto por três sítios todos adaptados para cadeirantes: Baixão das Andorinhas, local onde todas as tardes, ao cair o sol, as andorinhas se reúnem no alto, dando voltas e, de repente, mergulham em alta velocidade, entrando por pequenos buracos em cavernas; Toca do Baixão do Perna I, que é um abrigo situado na margem do vale do Baixão do Perna; e a Toca do Baixão do Perna II, um sítio típico no qual os homens préhistóricos aproveitaram uma plataforma rochosa para acampar e realizar as pinturas rupestres. Destes, somente o Baixão das Andorinhas tem acesso pavimentado de cimento desde o local de estacionamento até o sítio, além de rampas, com largura de 1,30m e espaço para manobras de cadeiras de rodas. As duas Tocas do Baixão do Perna somente tem adaptação no local do sítio.

Assim, percebeu-se que dos 52 sítios arqueológicos visitados, distribuídos nos seis circuitos mais procurados no PNSC, segundo informações fornecidas pelos condutores de visitantes, apenas 16 tem algum tipo de adaptação para deficientes e pessoas com mobilidade reduzida, principalmente, para cadeirantes. O restante dos sítios abertos à visitação pública, 74, não possuem adaptação e sua maioria é voltada para a prática de atividades de aventura, conforme informação dos condutores. Este dado revela que somente $30 \%$ dos sítios pesquisados são 
parcialmente adaptados, o que corresponde a $12 \%$ do total de sítios abertos à visitação pública.

Notou-se, também, que em sete, dos 16 sítios adaptados, só há rampas de acesso aos sítios, ou seja, os trajetos até os mesmos não são adaptados. As trilhas até estes locais não são pavimentadas de material liso e antiderrapante; são trilhas carroçais, não compatíveis para a movimentação tanto de cadeirantes quanto de pessoas com dificuldade de locomoção. Constatou-se, através das observações diretas e medições, que nem todas as rampas de acesso dos sítios adaptados, seguem as orientações da ABNT, já mencionadas anteriormente no que diz respeito à largura.

Em relação aos sanitários do Centro de Visitantes, não há adaptação. Todavia, nos sanitários das guaritas há adaptação, entretanto não há a SIA, indicando que aquele local está adaptado e é reservado para pessoas com deficiência ou mobilidade reduzida, contando com barras de apoio e largura necessária. Na lanchonete do Centro, a altura do balcão de atendimento está $30 \mathrm{~cm}$ acima da obrigatória e com exposição de objetos $15 \mathrm{~cm}$ acima do permitido.

No estacionamento do Circuito do Boqueirão da Pedra Furada, o único com divisão de vagas, não há locais reservados a deficientes, o piso é irregular e ainda há um desnível para se ter acesso a trilha (pavimentada com cimento). Isso foge todas as recomendações do Decreto Federal Decreto $n^{\circ} 5.296 / 2004$ e da ABNT.

Em relação à sinalização do Parque, identificou-se que em 42 sítios pesquisados (80\%) só existem placas com o nome do sítio, escritas com letras pequenas em cor amarela e fundo preto. Esse tipo de placa não se adapta às necessidades tanto de deficientes visuais, devido às dificuldades de leitura, quanto de deficientes auditivos, devido à falta de informação sobre os sítios. Existem ainda placas indicativas de direção, com letras maiores na cor branca e fundo verde (Figura 3). 


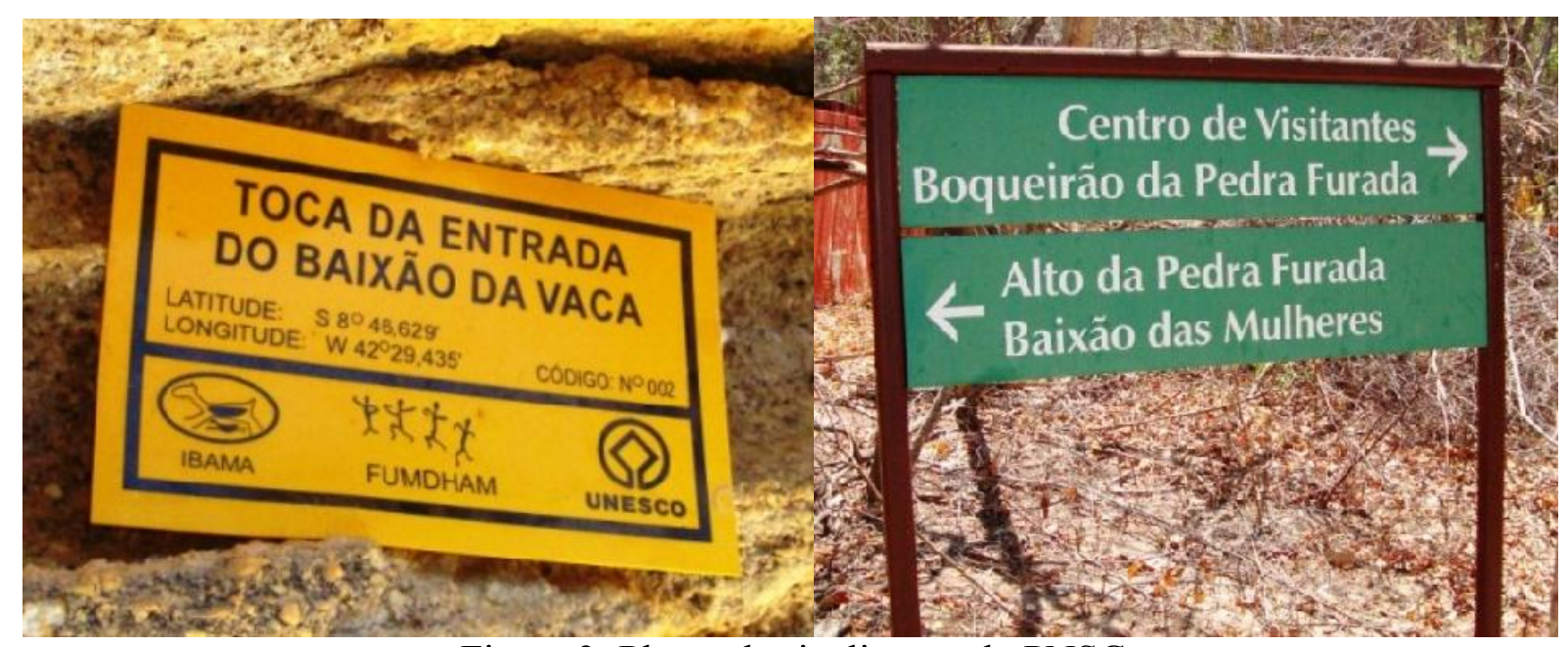

Figura 3: Placas de sinalização do PNSC

Fonte: arquivo pessoal (set./2010).

Em nenhum dos sítios pesquisados, encontrou-se qualquer placa informativa em Braille e/ou em letras grandes e nem sinalização tátil nos pisos. Boa parte das trilhas não é pavimentada o que dificulta este tipo de adaptação. Entretanto, para torná-las mais acessíveis para deficientes visuais, em algumas dessas trilhas poderiam ser instaladas cordas para facilitar a sua locomoção, placas informativas em Braille e com letras grandes (para pessoas com baixa visão), maquetes dos principais sítios arqueológicos, com algumas pinturas em Braille, e bonecos de algumas espécies da fauna e flora da região. Isso colocaria os visitantes deficientes visuais com um maior contato com o espaço natural e arqueológico, além de proporcioná-los uma experiência turística diferenciada.

Já para os deficientes auditivos, as barreiras se encontram, basicamente, na comunicação. Segundo dados coletados em entrevistas com os condutores de visitantes do Parque, nenhum dos condutores da ACOVESP tem conhecimento sobre LIBRAS, então a comunicação aconteceria de maneira improvisada. Esta barreira seria menor se nos sítios arqueológicos houvesse placas interpretativas, ou seja, placas auto-explicativas com informações gerais sobre o sítio. Entretanto, constatou-se que somente em 10 sítios existem placas desse tipo, porém, em péssimo estado de conservação, mal formatadas, com excesso de textos e uso de linguagem científica, o que não é nada didática para visitações em locais ao ar livre, com os mais variados perfis de visitantes. A solução seria capacitar os condutores para melhor 
atender esse tipo de deficiente, ensiná-los a linguagem dos sinais ou confeccionar novas placas interpretativas e fixá-las nos principais sítios.

Em relação aos condutores, de acordo com dados obtidos em entrevistas e conversas informais, alguns deles já tiveram contato com cadeirantes e deficientes auditivos, porém não se sabe ao certo quantas pessoas foram, pois não se tem registro dessas informações. Entretanto, ainda segundo os próprios condutores, em entrevistas, no período da pesquisa de campo deste trabalho, de julho a setembro de 2010, das 4.032 pessoas que visitaram o PNSC (dados de registro de visitantes obtidos no ICMBio), nenhuma era deficiente. Todavia, isso não significa dizer que não haja público de deficientes ou com mobilidade reduzida que poderiam visitar o Parque, caso houvesse uma melhor infraestrutura de adaptação.

\section{Conclusão}

O desenvolvimento dessa pesquisa procurou identificar e analisar infraestrutura dos principais sítios abertos a visitação pública do Parque Nacional Serra da Capivara, que divulga em folders informativos e nas próprias placas de sinalização do mesmo, a presença de sítios adaptados.

Entretanto, após a pesquisa de campo, constatou-se, por meio de observações diretas e medições in loco, que o local não é adaptado para os mais diversos tipos de deficiência. As únicas adaptações existentes são encontradas em 16 sítios arqueológicos (12\% do total de sítios abertos ao público), voltadas principalmente para cadeirantes. Nestes locais, foram instaladas algumas melhorias na acessibilidade dos sítios, como: trilhas de acesso com pavimentação em cimento, rampas de acesso às passarelas de observação e locais de manobras das cadeiras de rodas. Porém, constatou-se que estas adaptações, que foram entregues em abril de 2006, pelo IPHAN e pela FUMDHAM (conforme informações coletadas em entrevistas), não atendem todas as recomendações exigidas pela NBR 9050:2004, da ABNT, e nem pelos Decretos Federais n. ${ }^{\circ}$ 914/1993 e n ${ }^{\text {o }} 5.296 / 2004$, no que diz respeito à largura de calçadas e balcões de atendimento, estacionamento, sanitários, entre outros. 
Percebeu-se, também, que a sinalização informativa dos sítios não favorece as pessoas com deficiência visual, que não há a utilização da SIA nas portas dos sanitários e nem nos estacionamentos. Notou-se, também, a existência na lanchonete do Centro de Visitantes de um balcão de altura superior ao permitido.

No geral, o Parque conta com diversas passarelas e corrimões ao longo dos principais sítios, mas na maioria desses locais, ainda existem degraus, com alturas variáveis, porém, são identificados com faixas amarelas, proporcionando uma maior segurança para os visitantes.

Segundo informações repassadas em entrevistas por responsáveis do IPHAN, ICMBio e FUMDHAM, não há previsão para futuras adaptações além das já existentes. Entretanto, é importante destacar que a escassez de recursos financeiros destinados para melhorias na infraestrutura do Parque contribuiu para a inobservância das normas técnicas quando da realização das adaptações ora existentes. Por ser um parque nacional, os recursos para a manutenção são limitados tendo em vista que a maioria dos visitantes (66\%) é constituída por estudantes, professores e pesquisadores e, portanto, não-pagantes (ICMBio). Todavia, se novas adaptações forem implementadas e feitas melhorias na infraestrutura existente, o PNSC poderá absorver este novo segmento de mercado turístico: o acessível. Isto poderia atrair mais recursos financeiros para o Parque, além de se tornar referência neste tipo de turismo, assim como acontece na cidade de Socorro - SP.

Portanto, espera-se que esta pesquisa desperte o interesse dos gestores e empresários da região do Parque Nacional Serra da Capivara - PI em torná-lo mais acessível para todas as pessoas, atraindo cada vez mais visitantes, movimentando a economia local e gerando empregos e renda.

\section{Referências}

ABNT. NBR 9050:2004 - Acessibilidade a edificações, mobiliário, espaços e equipamentos urbanos. Rio de Janeiro, 2004. 2008. . NBR 15599:2008 - Acessibilidade - Comunicação na prestação de serviços. Rio de Janeiro,

AGUIRRE, R. S. Recreação e turismo para todos. Rio de Janeiro: Educs, 2003.

ARAÚJO, J. L. L. (Coord.). Atlas escolar do Piauí: geo-histórico e cultural. João Pessoa, PB: Editora Grafset, 2006. 
ARRUDA, M. B. Conservação, ecologia humana e sustentabilidade na caatinga: estudo da região do Parque Nacional da Serra da Capivara (PI). Brasília: Instituto Brasileiro do Meio Ambiente e dos Recursos Naturais Renováveis, 1997.

BORGES, A. B. de A. Acessibilidade e desenvolvimento sustentável: o turismo na cidade de Formosa - GO. Brasília: UnB, 2009. 59 f. Monografia (Especialização). Pós-Graduação em Formação de Professores em Turismo da Universidade de Brasília (Centro de Excelência em Turismo). Brasília, 2009.

BRASIL. Decreto Federal $n^{\circ}$ 914, de 6 de Setembro de 1993. Disponível em: $<$ http://www.planalto.gov.br/ccivil_03/decreto/d0914.htm>. Acesso em: 25 set. 2010.

Decreto Federal $n^{\circ}$ 5.296, de 2 de Dezembro de 2004. Disponível em: $\overline{<\mathrm{http} / / /}$ www.planalto.gov.br/ccivil/_ato2004-2006/2004/decreto/d5296.htm>. Acesso em: 25 set. 2010.

Lei Federal $n^{\circ}$ 9.985, de 18 de Julho de 2000a. Disponível em:

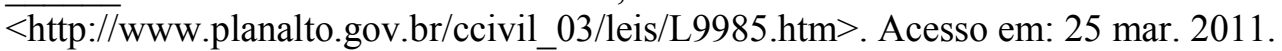

Lei Federal $n^{o}$ 10.098, de 19 de Dezembro de 2000b. Disponível em: $<$ http://www.planalto.gov.br/ccivil_03/leis/L10098.htm>. Acesso em: 25 mar. 2011.

Lei Geral do Turismo, $\mathrm{n}^{\mathrm{o}} 11.771$ de 17 de setembro de 2008. Disponível em: < http://www.planalto.gov.br/ccivil_03/_ato2007-2010/2008/lei/111771.htm>. Acesso em: 25 mar. 2011.

Ministério do Turismo. Cartilha Dados no Turismo Brasileiro. Brasília: Ministério do Turismo, 2011.

. Ministério do Turismo. Estudo de Competitividade dos 65 Destinos Indutores do Desenvolvimento Turístico Regional - Relatório Brasil. Luiz Gustavo Medeiros Barbosa (Organizador). — 2 ed. Revisada. Brasília: Ministério do Turismo, 2008.

. Ministério do Turismo. Plano Nacional do Turismo 2007/2010 - Uma viagem de inclusão. Brasília: Ministério do Turismo, 2007.

. Ministério do Turismo. Turismo e acessibilidade: Manual de Orientações. Brasília: Ministério do Turismo, 2006.

. Ministério do Turismo. Turismo Acessivel: Introdução a uma Viagem de Inclusão. v. 1. Brasília: Ministério do Turismo, 2009a.

Ministério do Turismo. Turismo Acessivel: Mapeamento e Planejamento do Turismo Acessível nos Destinos Turísticos. v. 2. Brasília: Ministério do Turismo, 2009b.

. Ministério do Turismo. Turismo Acessivel: Bem Atender no Turismo Acessível. v. 3. Brasília: Ministério do Turismo, 2009c.

BUHALIS, D.; EICHHORN, V. Market analysis and commercialisation of the OSSATE e - service. IN: OSSATE 2nd International Workshop, Atenas, Grécia, 2005. Disponível em: $<$ http://www.ossate.org/library-news $>$. Acesso em: 20 abr. 2011.

BUTLER, R.; JONES, P. Conclusões - Problemas, Desafios e Soluções. IN: LOCKWOOD, A.; MEDLIK, S. Turismo e Hospitalidade no século XXI. Barueri, SP: Manole, 2003. p. 309-322.

CARMO, A. A. do. Deficiência física: a sociedade brasileira cria e descrimina. Brasília: Secretaria dos Desportos, 1991.

CONSTANT, I. B. Recursos para melhorar a visão. Disponível em: $<$ http://www.ibc.gov.br/?catid=150\&blogid=1\&itemid=10172>. Acesso em: 15 mai. 2011. 
FUMDHAM. Fundação Museu do Homem Americano: O museu do homem americano. São Raimundo Nonato/PI: FUMDHAM, 1998.

. O Parque Nacional Serra da Capivara. Disponível em: <http://www.fumdham.org.br/>. Acesso em: 25 set. 2010.

GOULART, R. R. As viagens e o turismo pelas lentes do deficiente físico praticante de esporte adaptado: estudo de caso. Caxias do Sul: UCS, 2007. 116 f. Dissertação (Mestrado). Programa de PósGraduação em Turismo da Universidade de Caxias do Sul. Caxias do Sul - RS, 2007.

IBGE. Censo demográfico 2010 - Resultados preliminares. Disponível em: $<$ http://www.sidra.ibge.gov.br/bda/tabela/protabl.asp?c=3326\&z $=$ cd\&o=7\&i=P $>$. Acesso em: 29 fev. 2012.

PANOSSO, A.; PANNO, G. Turismo e acessibilidade na cidade de São Paulo: da teoria à prática. Revista Itinerarium, $\quad 2010.3, \quad$ Disponível em: $<$ http://www.seer.unirio.br/index.php/itinerarium/article/viewArticle/1265>. Acesso em: 25 mar. 2011.

OLIVEIRA FILHO, R. C. de. Valoração econômica da atividade ecoturística no Parque Nacional Serra da Capivara - PI. Teresina: UFPI, 2007. 183 f. Dissertação (Mestrado). Programa Regional de Pós-Graduação em Desenvolvimento e Meio Ambiente da Universidade Federal do Piauí (PRODEMA/UFPI/TROPEN). Teresina, 2007.

ONU. Resolução n48/96, de 20 de dezembro de 1993 - Normas sobre Equiparação de Oportunidades para Pessoas com Deficiência. Disponível em: $<$ http://www.ampid.org.br/Docs_PD/Convencoes_ONU_PD.php\#normas1>. Acesso em: 25 set. 2010.

PIAUÍ. GOVERNO DO ESTADO. Região Polo Histórico-Cultural realiza seminário sobre turismo. Disponível em: <http://www.piaui.pi.gov.br/materia.php?id=34623>. Acesso em: 20 abr. 2011.

RULLI, A. Direitos dos portadores de necessidades especiais. São Paulo: Fiúza, 2002.

SÁ, E. D. de. Necessidades educacionais especiais. Disponível em: $<$ http://www.bancodeescola.com/verbete4.htm>. Acesso em: 23 fev. 12.

SASSAKI, R. K. Inclusão: construindo uma sociedade para todos. 6. ed. Rio de Janeiro: WVA, 2005. . Inclusão no lazer e turismo em busca da qualidade de vida. São Paulo: Áurea, 2003.

Necessidades especiais -6 de agosto de 2010. Disponível em: $\overline{<\mathrm{http} / / /}$ www.deficienteciente.com.br/2010/08/necessidades-especiais.html>. Acesso em: 23 fev. 12.

. Terminologia sobre deficiência na era da inclusão. Revista Nacional de Reabilitação, ano 5, n. 24, jan./fev. 2002. Disponível em: $<$ http://www.mp.pe.gov.br/uploads/kW3CahiaDqoM7XQvftRxHQ/MtoCzxLxzPWZN1IZIHhyuw/ter minologia_inclusiva.pdf $>$. Acesso em: 23 fev. 2012.

UNESCO. Lista do Patrimônio Mundial no Brasil. Disponível em: $<$ http://www.unesco.org/new/pt/brasilia/culture/world-heritage/list-of-world-heritage-inbrazil/\#c154844>. Acesso em 25 fev. 2012.

\section{Recebido em: 07/03/2011}

Aprovado em: 27/06/2011 (1 ${ }^{\mathrm{a}}$ versão) $06 / 06 / 2012\left(2^{\mathrm{a}}\right.$ versão) 